\title{
Discrepancies between physician interview and a patient self-assessment questionnaire after surgery for pelvic organ prolapse
}

\author{
T. A. de Boer • D. A. Gietelink • M. E. Vierhout
}

Received: 29 February 2008 / Accepted: 29 April 2008 / Published online: 29 May 2008

(C) The Author(s) 2008

\begin{abstract}
The objective of this article was to investigate whether there were discrepancies between the physician interview and a patient's self-assessment questionnaire on the functional results after surgery for pelvic organ prolapse. Before their follow-up appointment, 79 patients were sent a validated urogynaecological questionnaire. At the follow-up visit, the physician interviewed the patients using a checklist with ten symptoms and scored the items as present or absent. Seventy-two patients (91.1\%) attended the follow-up visit and had completed the questionnaire. There was poor to slight agreement between the interview score and the self-reported responses to the questionnaire on all items. This was illustrated by low kappa coefficients. The physician was more optimistic about the outcome of the operation than was justified according to the answers to a patient self-assessment questionnaire. We therefore recommend the use of validated questionnaires to evaluate surgical outcome because they provide a more realistic (objective) view of the functional results.
\end{abstract}

Keywords Interview $\cdot$ Patient $\cdot$ Physician $\cdot$ Prolapse $\cdot$ Questionnaire· Self-assessment

\author{
Abbreviations \\ POP Pelvic organ prolapse \\ IIQ-7 Incontinence Impact Questionnaire
}

UDI-6 Urogenital Distress Inventory

DDI Defaecatory Distress Inventory

\section{Introduction}

It is essential to evaluate quality of life and the functional results after prolapse surgery [1]. Traditionally, the physician evaluates the outcome by interviewing and examining the patient. In clinical studies, these data are often obtained by a (self-report) questionnaire.

Several studies showed discrepancies in the interpretation of surgical outcome between the physician and the patient [2]. Physicians tended to underestimate the degree of bother in $25-37 \%$ of the patients [1]. The evaluation of the severity of the complaints of incontinence before treatment showed contradictory results between patient and physician $[3,4]$.

Although the above-mentioned aspects have been studied in relation with various surgical interventions, no data are available on the outcome of pelvic organ prolapse (POP) surgery. As POP surgery is an important and growing field of interest, we investigated whether there were discrepancies between the interview recorded by the physician and the answers to a patient self-assessment questionnaire on the functional results after POP surgery.

\section{Materials and methods}

Several weeks before the 1-year follow-up appointment, the standard urogynaecological questionnaire (proposed by the Pelvic Floor Committee of the Dutch Gynaecological Society) was sent to all the patients who had undergone
T. A. de Boer $(\bowtie) \cdot M$. E. Vierhout

Department of Obstetrics and Gynaecology,

Radboud University Medical Centre,

P.O. Box 9101, 6500 HB Nijmegen, The Netherlands

e-mail: T.deBoer@obgyn.umcn.nl 
Table 1 Patient characteristics

\begin{tabular}{lcl}
\hline & Number of patients & Values \\
\hline Age (years) median and range & 72 & $66.6[37-87]$ \\
Parity median and range & 72 & $2[0-9]$ \\
Recurrence & 47 & $65.3 \%$ \\
Degree of prolapse (Baden Walker) & & \\
Grade 2 & 3 & $4.2 \%$ \\
Grade 3 & 64 & $88.9 \%$ \\
Grade 4 & 5 & $6.9 \%$ \\
Use of Pelvicol ${ }^{\circledR}$ & & \\
Anterior & 21 & $29.2 \%$ \\
Posterior & 35 & $48.6 \%$ \\
Anterior and posterior & 16 & $22.2 \%$ \\
\hline
\end{tabular}

vaginal repair POP surgery with porcine denatured dermal collagen $\left(\right.$ Pelvicol $\left.^{\circledR}\right)$ between December 2003 and August 2005. Details of the study population and procedures are presented in Table 1.

The patient self-assessment questionnaire is a combination of well-known internationally used validated questionnaires which are all validated for the Dutch language containing questions on general quality of life and health, derived from the Dutch version of the Euroqol 5D, [5] disease-specific questions from the validated Dutch translation of the Incontinence Impact Questionnaire (IIQ-7) [6] and Urogenital Distress Inventory (UDI-6) [6] and questions from the Defaecatory Distress Inventory (DDI) [7]. If a specific symptom is present, the patient is asked to rate the amount of bother it was causing her on a four-point Likert scale. The complete Dutch language standardised version of this questionnaire has been validated [8]. In addition, two questions were included about urinary symptoms, derived from the Patient Global Impression of Improvement Scale [9].
At the 1-year follow-up visit, all the patients were interviewed by the same surgeon who had performed the surgery, using a checklist with ten symptoms (Table 2). Items were scored as present or absent. The physician was unaware of the patient self-assessment responses to the questionnaire.

The data obtained with the interviews and the questionnaire were entered into an SPSS 13.0 database. Statistical analyses were performed using Cohen's kappa coefficient, which is a statistical measure of inter-rater agreement. Kappa takes into account the agreement that occurs by chance. When raters are in complete agreement, kappa is 1 . If there is no agreement, other than that expected by chance, then kappa is 0 . Also, the $95 \%$ confidence interval for kappa is calculated. For the statistical analyses, SPSS 13.0 and SAS version 8.2 were used.

\section{Results}

A total of 79 patients were sent the questionnaire and invited for a 1-year follow-up visit. Interview and questionnaire data were available for analysis in 72 patients (response rate 91.1\%). Reasons for not attending were illness and living in a foreign country, and one patient had died from another illness.

Mean age of the participants was 66.6 years (range 37$87) ; 65.3 \%$ had undergone surgery because of recurrent prolapse. Table 2 shows the differences in ratings on ten items between the interview scores recorded by physician and the patient self-assessments on the questionnaire. The results of the analysis are shown in Table 3. We found bidirectional differences in opinion between the physician and the patient: there was underestimation on eight items and overestimation on two items. The low kappa coef-

Table 2 Inter-rater discrepancies between the physician and the patient

\begin{tabular}{|c|c|c|c|c|c|c|c|c|}
\hline & \multicolumn{4}{|c|}{ Physician no } & \multicolumn{4}{|c|}{ Physician yes } \\
\hline & \multicolumn{2}{|c|}{ Patient no } & \multicolumn{2}{|c|}{ Patient yes } & \multicolumn{2}{|c|}{ Patient no } & \multicolumn{2}{|c|}{ Patient yes } \\
\hline & $N$ & $\%$ & $N$ & $\%$ & $N$ & $\%$ & $N$ & $\%$ \\
\hline Urinary stress incontinence & 35 & 50.0 & 20 & 28.6 & 2 & 2.9 & 13 & 18.6 \\
\hline Urinary urge & 24 & 34.3 & 27 & 38.6 & 6 & 8.6 & 13 & 18.6 \\
\hline Urinary Urge incontinence & 30 & 42.3 & 27 & 38.0 & 1 & 1.4 & 13 & 18.3 \\
\hline Frequency micturition & 35 & 52.2 & 28 & 41.8 & 1 & 1.5 & 3 & 4.5 \\
\hline Nocturia & 10 & 14.7 & 4 & 5.9 & 21 & 30.9 & 33 & 48.5 \\
\hline Urinary retention & 36 & 50.7 & 25 & 35.2 & 4 & 5.6 & 6 & 8.5 \\
\hline Constipation & 47 & 73.4 & 3 & 4.7 & 11 & 17.2 & 3 & 4.7 \\
\hline Urge for defaecation & 33 & 48.5 & 31 & 45.6 & 2 & 2.9 & 2 & 2.9 \\
\hline Faecal evacuation difficulties & 54 & 80.6 & 7 & 10.4 & 2 & 3.0 & 4 & 6.0 \\
\hline Flatal incontinence & 21 & 32.4 & 28 & 43.1 & 1 & 1.5 & 15 & 23.1 \\
\hline
\end{tabular}


Table 3 Analysis of inter-rater discrepancies between the physician and the patient

\begin{tabular}{|c|c|c|c|c|c|c|c|}
\hline & Sample & Missing & Discordance & Kappa & $95 \% \mathrm{CI}$ & & $P$ \\
\hline Urinary stress incontinence & 70 & 2 & 22 & 0.350 & 0.161 & 0.540 & 0.001 \\
\hline Urinary urge & 70 & 2 & 33 & 0.115 & -0.074 & 0.304 & 0.244 \\
\hline Urinary urge incontinence & 71 & 1 & 28 & 0.268 & 0.111 & 0.424 & 0.002 \\
\hline Frequency micturition & 67 & 5 & 29 & 0.073 & -0.052 & 0.199 & 0.235 \\
\hline Nocturia & 68 & 4 & 25 & 0.224 & 0.023 & 0.426 & 0.029 \\
\hline Urinary retention & 71 & 1 & 29 & 0.101 & -0.080 & 0.282 & 0.261 \\
\hline Constipation & 64 & 7 & 14 & 0.194 & -0.078 & 0.466 & 0.080 \\
\hline Urge for defaecation & 68 & 4 & 33 & 0.004 & -0.111 & 0.118 & 0.952 \\
\hline Faecal evacuation difficulties & 67 & 6 & 9 & 0.401 & 0.090 & 0.712 & 0.000 \\
\hline Flatal incontinence & 65 & 7 & 29 & 0.233 & 0.085 & 0.382 & 0.007 \\
\hline
\end{tabular}

ficients on all items illustrated poor to slight agreement between the patients and the physician. Table 4 shows the amount of bother reported by patients in the group whose complaints were underestimated by the physician.

Table 5 shows the responses to the Patient Global Impression of Improvement Scale question about urinary tract functioning before and after the operation in the group of patients whose complaints were underestimated by the physician. Most of the patients reported improvement in their symptoms after the operation.

\section{Discussion}

There were large discrepancies in the judgements of functional outcome between the physician-based interview data and the self-report answers to the questionnaire given by the patients. This is best illustrated by the low kappa coefficients. The physician showed a strong tendency to underestimate the complaints of the patients. This phenom-

Table 4 Amount of bother reported by the patients in the physician no/patient yes group whose complaints were underestimated by the physician

\begin{tabular}{|c|c|c|c|c|}
\hline & \multicolumn{2}{|c|}{$\begin{array}{l}\text { Little or no } \\
\text { bother }\end{array}$} & \multicolumn{2}{|c|}{$\begin{array}{l}\text { Moderate to severe } \\
\text { bother }\end{array}$} \\
\hline & $N$ & $\%$ & $N$ & $\%$ \\
\hline Urinary stress incontinence & 16 & 80.0 & 4 & 20.0 \\
\hline Urinary urge & 17 & 63.0 & 10 & 37.0 \\
\hline Urinary urge incontinence & 22 & 81.5 & 5 & 18.5 \\
\hline Frequency micturition & 15 & 53.6 & 13 & 46.4 \\
\hline Nocturia & 2 & 50.0 & 2 & 50.0 \\
\hline Urinary retention & 23 & 92.0 & 2 & 8.0 \\
\hline Constipation & 1 & 33.3 & 2 & 66.7 \\
\hline Urge for defaecation & 20 & 64.5 & 11 & 35.5 \\
\hline Faecal evacuation difficulties & 6 & 85.7 & 1 & 14.3 \\
\hline Flatal incontinence & 21 & 75.0 & 7 & 25.0 \\
\hline
\end{tabular}

enon is well known in gynaecological follow-up studies and in other fields of medicine [1, 2, 4, 10, 11].

There are several possible explanations for the differences in judgement between the physician and the patients.

First, the complaints may be relatively slight and therefore not mentioned by the patient in the interview. In this study, this was valid in a considerable proportion of the patients. Table 4 shows that roughly two thirds of the patients who had a positive score on a specific complaint on the questionnaire versus a negative score from the physician (physician no/patient yes group) had slight to moderate complaints reported in the questionnaire.

We see that, on a few topics, some missing data are found, which might indicate that these patients had problems with understanding these questions. However, we only used questions from validated questionnaires; therefore, misinterpretation of the questions by the patients is unlikely to be an explanation. The semantics of the questions asked by physician were not monitored and could be an important factor. A question might be formulated slightly differently by the physician than in the questionnaire. If the physician asks the patient about a complaint, he might say: "Do you ever have complaints about...?", while the questionnaire formulates the same question as: "Do you

Table 5 Average improvement in urinary symptoms compared to before the operation according to Patients Global Impression of Improvement Scale in the physician no/patient yes group

\begin{tabular}{lccccc}
\hline & \multicolumn{2}{c}{ Better } & & \multicolumn{2}{c}{ Unchanged or worse } \\
\cline { 2 - 3 } & $N$ & $\%$ & & $N$ & $\%$ \\
\hline Urinary stress incontinence & 13 & 65.0 & & 7 & 35.0 \\
Urinary urge & 19 & 73.1 & & 7 & 26.9 \\
Urinary urge incontinence & 19 & 70.4 & 8 & 29.6 \\
Frequency micturition & 20 & 74.1 & & 7 & 25.9 \\
Nocturia & 4 & 100 & & 0 & 0 \\
Urinary retention & 18 & 72.0 & 7 & 28.0 \\
\hline
\end{tabular}


ever have the following symptoms?" In this way, the physician will hear about the patient's complaints, whereas the questionnaire scores the symptoms.

Another possible explanation is what we call the "waiter effect". In general, people are reluctant to complain after a meal, even when it was unsatisfactory, because they consider this to be impolite. Along these lines, Hall et al. [12] reported that a patient may believe that being liked is one way to ensure prompt, conscientious, thorough and considerate care. Being a good patient is motivated by the desire to obtain goodwill by minimising the burden placed on health care providers, so that care would be forthcoming when it was really needed [12-14].

Another explanation is that a specific symptom has improved, which suppresses its importance during the interview, although the symptom is still present. We compared the surgical outcome to the original situation using a question from the Patient Global Impression of Improvement Scale. Table 5 shows that the physician no/ patient yes group (Table 4) had an average improvement of $72.1 \%$ compared to that before the operation.

Symptoms may have changed in the time between filling in the questionnaire at home and being interviewed by the physician. Although we did not record this time specifically, it is unlikely to be an important factor because the questionnaires were sent to the patients only a few weeks before their visit to the outpatient department.

Physicians tend to overestimate their own surgical results [15]. If an independent physician had interviewed the patients, the results might have been different. However, this would have been contrary to normal clinical practice.

Distress and embarrassment during the interview could lead to denial of symptoms in order to escape awkward situations. However, our patients knew their physician well, so there was less likelihood of hesitance. In the literature, conflicting information is given about how embarrassment influenced the results $[16,17]$.

\section{Conclusion}

The physician was more optimistic about the outcome of the operation than was justified according to the answers to the patient self-assessment questionnaire. We therefore recommended the use of validated self-assessment questionnaires in clinical studies and to evaluate surgical outcome because they help to obtain a more realistic view of the functional results.

\section{Conflicts of interest None.}

Open Access This article is distributed under the terms of the Creative Commons Attribution Noncommercial License which permits any noncommercial use, distribution, and reproduction in any medium, provided the original author(s) and source are credited.

\section{References}

1. Srikrishna S, Robinson D, Cardozo L, Gonzalez J (2008) Is there a difference in patient and physician quality of life evaluation in pelvic organ prolapse? Int Urogynecol J Pelvic Floor Dysfunct 19 (4):517-520

2. Lieberman JR, Dorey F, Shekelle P, Schumacher L, Thomas BJ, Kilgus DJ et al (1996) Differences between patients' and physicians' evaluations of outcome after total hip arthroplasty. J Bone Joint Surg 78-A:835-838

3. Melville JL, Miller EA, Fialkow MF, Lentz GM, Miller JL, Fenner DE (2003) Relationship between patient report and physician assessment of urinary incontinence severity. Am J Obstet Gynecol 189:76-80

4. Yalcin I, Viktrup L (2007) Comparison of physician and patient assessments of incontinence severity and improvement. Int Urogynecol J Pelvic Floor Dysfunct 18(11):1291-1295

5. Brooks R, Rabin R, de Charro F (2003) The measurement and valuation of health status using EQ-5D: a European perspective. Kluwer, Dordrecht

6. Uebersax JS, Wymman JF, Shumaker SA, McClish DK, Fantl JA (1995) Short forms to assess life quality and symptom distress for urinary incontinence in women: the Incontinence Impact Questionnaire and the Urogenital Distress Inventory. Neurourol Urodyn 14:131-139

7. van Brummen HJ, Bruinse HW, van de Pol G, Heintz AP, van der Vaart CH (2006) Defecatory symptoms during and after the first pregnancy: prevalences and associated factors. Int Urogynecol J Pelvic Floor Dysfunct 17(3):224-230

8. van der Vaart CH, de Leeuw JR, Roovers JP, Heintz AP (2003) Measuring health-related quality of life in women with urogenital dysfunction: the Urogenital Distress Inventory and Incontinence Impact Questionnaire revisited. Neurourol Urodyn 2(2):97-104

9. Yalcin I, Bump RC (2003) Validation of two global impression questionnaires for incontinence. Am J Obstet Gynecol 189(1):98 101

10. Rodriguez LV, Blander DS, Dorey F, Raz S, Zimmern P (2003) Discrepancy in patient and physician perception of patient's quality of life related to urinary symptoms. Urology 62:49-53

11. Scheuer E, Steurer J, Buddeberg C (2002) Predictors of differences in symptom perception of older patients and their doctors. Fam Pract 19:357-361

12. Hall JA, Horgan TG, Stein TS, Roter DL (2002) Liking in the physician-patient relationship. Patient Educ Couns 48(1):69-77

13. Cartwright A (1967) Patients and their doctors. Routledge \& Kegan Paul, London

14. Cartwright A, Anderson R (1981) General practice revisited: a second study of patients and their doctors. Tavistock, London

15. Black N, Griffiths J, Pope C, Bowling A, Abel P (1997) Impact of surgery for stress incontinence on morbidity: cohort study. BMJ 315:1493-1498

16. Eisen SV (1995) Assessment of subjective distress by patient's self report versus structured interview. Psychol Rep 76:35-39

17. Hajebrahimi S, Corcos J, Lemieux MC (2004) International consultation on incontinence questionnaire short form: comparison of physician versus patient completion and immediate and delayed self-administration. Urology 63:1076-1078 